\title{
LA UNIVERSIDAD: ENTRE EL SABER Y LA DIGNIFICACIÓN DEL TRABAJO PROFESIONAL ANTE LOS RETOS DEL MERCADO
}

\section{THE UNIVERSITY: BETWEEN KNOWLEDGE AND DIGNIFICATION OF PROFESIONAL WORK IN THE FASE OF THE MARKET CHALLENGES}

Mariana Flores Rabasa ${ }^{1}$

https:// orcid.org/0000-0002-6298-9104

Recibido: mayo 7, 2021 - Aceptado: mayo 27, 2021

\section{RESUMEN}

La universidad es un tipo de institución que, en su interacción con otras organizaciones sociales, conforma la sociedad civil. En tanto institución, posee un objetivo propio, a saber: la generación y transmisión de conocimiento en un contexto educativo, que permite distinguirla de otros agentes sociales. En tanto social, debe situar su vocación en relación y contraste con la finalidad de otras unidades de acción social, entre las que destaca preponderantemente el mercado.

El objetivo de esta reflexión es el de analizar los retos a los que se enfrenta la vocación de la universidad, ante las cada vez más demandantes necesidades del mercado que subrepticia o abiertamente se han introducido bajo un nuevo paradigma de generación de capital denominado «sociedad del conocimiento», así como una solución creativa para enfrentarlos, a través de la dignificación del trabajo profesional.

Palabras clave: universidad, sociedad del conocimiento, trabajo profesional, dignidad, mercado. 


\section{ABSTRACT}

The university is a type of institution that, in its interaction with other social organizations, makes up civil society. As an institution, it has its own objective, namely, the generation and transmission of knowledge in an educational context, which allows it to be distinguished from other social agents. As social, it must place its vocation in relation and contrast with the purpose of other social action units, among which the market stands out. The objective of the present paper is to analyze the challenges faced by the vocation of the university in the face of the increasingly demanding needs of the market that have been surreptitiously or openly introduced under a new paradigm of capital generation named «knowledge society», as well as a creative solution to face them through de dignity of professional work.

Keywords: University, Knowledge Society, Professional Work, Dignity, Market.

\section{INTRODUCCIÓN}

Existe una denuncia ya añeja, pero ampliamente extendida entre académicos de distintos lugares del mundo, que acusa al mercado como autor de numerosos temas de su agenda (García Fanelli, 2000), pues bajo el paradigma del neoliberalismo, la educación solo puede entenderse como la formación de capital humano (Connell, 2013), dando lugar a una reestructuración de la universidad en términos de lo que se ha llamado «capitalismo cognitivo», etiqueta con la que se busca resaltar las relaciones de dominación y explotación que subyacen a esta intromisión (Galcerán, 2007).

En efecto, hace ya algunas décadas que se vive una tensión entre la concepción tradicionalmente reconocida como misión esencial de esta institución, que radica en la formación de una mirada unificada y reflexiva de la realidad, desde y para la verdad (Newman, 1996), y una visión contrapuesta, que la concibe como una corporación inserta en un mercado competitivo para producir y vender bienes o servicios, mientras participa en el desarrollo económico a través del «entrenamiento» de fuerza de trabajo y de investigación productiva (Casanova, 2016). Por su parte, instancias oficiales de carácter internacional como la UNESCO admiten que, aunque el conocimiento se ha convertido en un pilar fundamental de la riqueza y el poder de las naciones, surge cierta tendencia-particularmente por parte de las economías más avanzadas del mundo- a considerarlo como simple mercancía, sujeta a las reglas del mercado y susceptible de apropiación privada. En este sentido, la universidad como institución no ha escapado a los efectos de la transformación del conocimiento y la información en fuerzas productivas que se han integrado al capital, pues cuando produce conocimientos destinados al aumento de informaciones para el capital financiero, inevitablemente queda sometida a sus necesidades y su lógica, situación particularmente señalada en las universidades latinoamericanas (Tünnermann y de Souza, 2003).

Así pues, en la primera parte de este trabajo me centraré en exponer críticamente cuáles son algunas de esas injerencias por parte del mercado, que han tomado forma preponderantemente bajo la figura de la sociedad del conocimiento propia del neoliberalismo como paradigma económico actualmente dominante. Tras llevar a cabo este repaso, en la segunda parte me daré a la tarea de explorar cuál puede ser el papel de la universidad ante los desafíos planteados, explorando la posibilidad de una educación liberal que sirva como catalizadora para dignificar el trabajo profesional, que permita ir más allá del trabajador 
cualificado exigido por los criterios pragmáticos del mercado, redescubriendo su esencia como bastión del saber y la búsqueda de la verdad, a la luz de esta tarea como agente imprescindible de transformación social.

\section{CRÍTICAS A LA MERCANTILIZACIÓN DE LA UNIVERSIDAD}

Un breve recorrido por la historia de la universidad, desde su nacimiento hasta los distintos paradigmas a los que ha estado sujeta desde entonces, da señas de una institución que, en un movimiento dialéctico, nació para cubrir las exigencias de su época y su contexto, al tiempo que fue capaz de trascenderlas para constituirse a sí misma como una especie de santuario atemporal del saber. El análisis de sus orígenes medievales da testimonio de que su función residió desde el principio, lo mismo en conservar y transmitir el conocimiento, que en atender la demanda de especialistas por parte de instituciones eclesiásticas y seculares, dotando a los juzgados y municipios de peritos especializados (Classen, 1983, como se citó en Rüegg, 1992, p. 11).

Hacia el comienzo de la denominada Baja Edad Media, y tras la revitalización de las ciudades, las crecientes necesidades burocráticas, tanto de la Iglesia como del reino, requirieron cada vez más de personas cualificadas en derecho canónico o civil por ejemplo, para las que ni la formación, ni el enfoque de la educación proporcionada en las escuelas monacales era ya suficiente. De ahí que, sin dejar de lado los beneficios asociados a la formación intelectual, tanto el papado como los reyes se interesarán en las universidades como una fuente idónea para el reclutamiento de personal adecuado para sus oficinas; sin duda, en el temprano siglo XII, la curia lo mismo que el reino, ya tenían claro el valor de la educación académica para la solución de problemas dogmáticos y legales (Rüegg, 1992, p. 16). Tal como se ve, la historia de la universidad muestra la génesis de una institución cuya genuina vocación por la creación y transmisión de conocimiento no surgió desligada de su vocación al servicio de las necesidades de la sociedad.

En la actualidad, la educación superior debe desarrollarse en el marco del capitalismo que de manera sintética se identifica tanto con los procesos de globalización como con las políticas neoliberales que lo acompañan. Siguiendo la definición propuesta por David Harvey (2005), el neoliberalismo

[...] es, ante todo, una teoría de prácticas político-económicas que afirma que la mejor manera de promover el bienestar del ser humano consiste en no restringir el libre desarrollo de las capacidades y de las libertades empresariales del individuo dentro de un marco institucional caracterizado por derechos de propiedad privada, fuertes mercados libres y libertad de comercio (p. 8).

Para economistas como Stiglitz, el neoliberalismo ha significado, por tanto, la definitiva mundialización de la economía -de modo que las naciones se articulan en torno a los mismos códigos económicos y políticos-, la conformación de conglomerados regionales y, sobre todo, la ampliación de las desigualdades entre las naciones y los diversos grupos sociales (Casanova y López, 2016, p. 42).

Bajo este escenario, existe cierto consenso de que la educación, como todo servicio público, ha pasado a identificarse como una mercancía, y en tanto tal, debe sujetarse a los vaivenes de la ley de la oferta y la demanda mundial, regional o local. El propio Harvey (2005) así lo sugiere cuando afirma que, en el marco del neoliberalismo, 
[...] en aquellas áreas en las que no existe mercado (como la tierra, el agua, la educación, la atención sanitaria, la seguridad social o la contaminación medioambiental), éste debe ser creado, cuando sea necesario, mediante la acción estatal. Pero el Estado no debe aventurarse más allá de lo que prescriban estas tareas (p. 8).

Por su parte, para Bob Brecher la extendida creencia de que el mercado es infalible en sus posibilidades de acceder al conocimiento, ha introducido una agenda neoliberal para las universidades pues «todo lo que cuenta como conocimiento es todo lo que se dice que predice el mercado» (Brecher, 2019, p. 134). Esto es claro bajo el paradigma de la denominada cuarta Revolución Industrial, un tipo de revolución tecnológica que ha dado lugar a la llamada sociedad del conocimiento, caracterizada por situar la creación de riqueza en la generación, posesión y utilización de determinado tipo de conocimientos, potencializada por las tecnologías de la información y la comunicación, y en donde el hacer tiene prioridad sobre el saber.

El paradigma de la sociedad del conocimiento ha trastocado de manera considerable el papel educativo y social de la institución universitaria al socavar las fuentes de la autoridad tradicional. Por una parte, aunque la universidad aún conserva su reconocimiento social como bastión para el encuentro con el saber, tanto el Estado como los poderes económicos le demandan una mayor funcionalidad en términos políticos y de mercado (Casanova y López, 2016, p. 45). Simultáneamente, la universidad debe competir con otros agentes productores de conocimiento, siendo incluso en muchos casos sustituida por aparatos informales de educación (Lanuza, 2021).

De hecho, la sociedad del conocimiento se caracteriza por una multiplicidad de fuentes de conocimiento de calidad diversa, por lo que el conocimiento no fluye exclusivamente desde las organizaciones académicas que conforman la educación superior. Desde luego, aquí encontramos Internet, un medio que permite acceder a una multiplicidad de información en tiempo récord, aunque como es obvio, no viene acompañado del criterio necesario para distinguir y discriminar, dentro del enorme abanico de posibilidades que ofrece para la documentación y el conocimiento.

Casanova y López (2016, pp. 44-45) añaden que otro factor de singular relevancia en el contexto emergente es el relativo a la aparición de nuevos saberes e instituciones. A la par del surgimiento de nuevos campos del conocimiento, o a la hibridación de campos en principio diferentes, continuamente aparecen instituciones paralelas a las universidades que también se ocupan de llevar a cabo tareas de investigación, docencia y difusión de la cultura.

Muestra de la diversificación institucional es la que refiere a la creación de modalidades universitarias, como la virtual y la corporativa. En la primera suelen combinarse saberes tradicionales con saberes innovadores; y aunque siguen teniendo cabida algunas formas tradicionales de operación, predomina el uso de tecnologías de nuevo cuño. En esta modalidad la base puede ser una institución tradicional que inicia un esquema dual, o puede ser una institución generada exclusivamente bajo el esquema virtual. Por otra parte, la modalidad corporativa es la que surge al amparo de una empresa o corporación que instituye una división universitaria a fin de proveerse de cuadros ejecutivos o directivos. Los saberes de tales corporativos están orientados al saber hacer y sus contenidos se orientan por los principios del gerencialismo.

En este sentido, no puede dejarse de lado el papel que juegan, en una economía centralizada en torno a la información y la innovación, las corporaciones de los más influyentes sectores de la actividad, cuya dimensión global, así como su aceleración operativa a través de 
la Red, han puesto en entredicho los esquemas más convencionales de formación. De hecho, estas mismas corporaciones son las que han propiciado la reconversión de las universidades en agentes creadores de valor agregado a través de una educación de posgrado, en la que, con frecuencia, la innovación se legitima desde la sede académica, una vez alumbrada y expandida en clave corporativa de vanguardia (cfr. Santos Rego, 2016). La aportación de la universidad en la sociedad del conocimiento consiste pues, en aportar la fuerza de trabajo necesaria para las corporaciones emanadas de la cuarta Revolución Industrial, que se traduce en términos de talento e innovación.

Un ejemplo de esta incidencia mercantil en la universidad es la orientación adoptada por las universidades europeas con la creación del Espacio Europeo de Educación Superior (EEES), iniciado en 1999 con el Proceso de Bolonia, y al que está suscrito el grueso de los países europeos. Con el objetivo de hacer frente a las demandas de la globalización y de la sociedad del conocimiento, el EEES nació como un esfuerzo por parte de la Unión Europea, para que las instituciones de educación superior realizaran cambios en las metodologías de enseñanza que pudieran mejorar la calidad de la educación superior en Europa, y los títulos superiores fueran comparables entre sí para favorecer la movilidad tanto de estudiantes como de profesorado. Entre estos cambios metodológicos se cuentan la consecución de resultados de aprendizaje en forma de competencias asociadas al mercado laboral, así como la centralidad del ejercicio educativo en la persona que aprende: el estudiante, en sustitución de la educación centrada en las materias y contenidos de enseñanza (Jover, 2016). Sin embargo, de acuerdo con Jover, esto significó que el concepto de competencia -que en realidad emana del ámbito de la formación y la gestión profesional- saltase durante los últimos años al terreno de la educación en general, y la enseñanza universitaria en particular, convirtiéndose en principal exponente de esa sociedad en la que el reconocimiento se valora por su rentabilidad práctica (2016, pp. 25-26).

Por otra parte, en una tesis más compleja y con una relación causal -que en mi opinión parece menos evidente-, la educación centrada en el alumno llevó a la promoción del llamado sistema de créditos ECTS (European Credit Transfer System) inicialmente adoptado en Europa en 1989, en el marco del programa Erasmus, como instrumento para la transferencia de créditos. Aunque su finalidad es promoverse como mecanismo que facilite el reconocimiento de los períodos de estudio realizados en otros países, basado en el trabajo que lleva a cabo el estudiante en la institución de acogida, el problema es que por una extraña conversión, este sistema dejó de tener un significado solo administrativo para convertirse en un supuesto principio pedagógico al que se apela para justificar un cambio de metodología docente, en el que el acento debe ponerse en el estudiante y su actividad, en lugar de atender al contenido de la enseñanza. De este modo, la versión pedagógica del sistema ECTS padece de un carácter contradictorio, pues si por un lado refuerza la imagen del estudiante como autor y sujeto de su formación, por otro puede fomentar también una visión clientelista del mismo, como consumidor que acumula, transfiere e invierte créditos en función de las demandas del mercado laboral (Jover, 2016, p. 32).

Esta sospecha se refuerza al atender a algunas mediciones en torno a la falta de movilización política por parte del alumnado de distintas universidades europeas, pues ello levanta la sospecha de que la idiosincrasia del alumno universitario se ha deslizado hacia la figura de un individuo que comienza y termina en él mismo, con poco interés por las problemáticas sociopolíticas que lo rodean y, por lo tanto, con poca capacidad de verdadera agencia social. Sin opacar las evidentes ventajas que conlleva una educación centrada en el estudiante -como, por ejemplo, la posibilidad de atender a su realidad y sus posibilidades, o el reconocimiento de su dignidad-, la cara opuesta de la moneda muestra una cultura universitaria en la que los estudiantes se autoconciben como clientes de un servicio, del que tienen derecho 
a demandar se adapte a sus necesidades según conveniencias que no solo se restringen al ámbito estrictamente académico.

Otra distorsión proveniente de la incidencia de los criterios utilitarios en la educación superior es que el modelo económico hegemónico vigente es ciego o indiferente ante los obstáculos, especialmente aquellos tecnológicos, que propician un desigual acercamiento al saber, profundizando y favoreciendo una verdadera mercantilización en términos de su acceso y disponibilidad. En particular es posible detectar fronteras bien definidas entre una población que puede acceder a los beneficios de la educación, y una periferia que queda varada en la frontera del conocimiento más elemental (Casanova y López, 2016).

En tal sentido, no resulta sorpresivo que la educación superior haya devenido en una mercancía mayormente accesible para las clases más privilegiadas de cada país (Casanova y López, 2016, p. 44), quienes justifican su triunfo bajo la vestimenta del mérito, sin advertir que ello no habría sido posible, paradójicamente, sin una situación de ventajas sociales y económicas que anteceden a la competencia académica. De este modo, la educación universitaria no permite combatir la desigualdad, sino que corre el peligro de cooperar involuntariamente en su consolidación. De acuerdo con Lanuza (2021), los propios padres tienden a mirar a sus hijos como inversión, y la educación es vista como el método para salir de la pobreza e incrementar ganancias, mientras que el acceso a ciertas universidades (piénsese por ejemplo en las universidades de la Ivy League) se ha convertido en la principal puerta de acceso al poder y prestigio.

Prueba de ello es el reciente escándalo de sobornos para entrar a renombradas universidades de Estados Unidos como Stanford y Yale, a manos de William Singer, cuyo fraude, recientemente puesto al descubierto, consistía en sobornar entrenadores y calificadores para que hijos de familias adineradas pudieran ingresar a una universidad privada de prestigio (Sandel, 2020). Al respecto, tiene sentido la denuncia de Michael Sandel al engaño meritocrático que también ha alcanzado a las universidades, pues existe la creencia generalizada de que la movilidad social está condicionada al grado obtenido gracias a los estudios universitarios, el cual supuestamente depende a su vez del propio esfuerzo personal cuando en realidad, solo los recursos facilitados por una cierta posición económica aventajada permiten de hecho el acceso a la educación superior, así como a la tecnología de la cual depende (situación que se ha hecho más evidente en la pandemia).

Así pues, una de las tensiones más características de la universidad del siglo XXI es la que involucra su acción ante el mercado. Se multiplican las demandas para que la institución se desempeñe de una manera mucho más definida como un elemento más del entramado industrial. Bajo la metáfora corporativa, la universidad como proveedora de trabajadores altamente capacitados -«capital humano» $\mathrm{O}$ «recursos humanos»-, estaría cada vez más lejos de su papel como formadora de sujetos críticos y actores sociales, comprometidos con el cultivo del conocimiento y la verdad. En términos del ámbito de la investigación, tal metáfora ha devenido en la demanda por un conocimiento de mayor «utilidad» y rentabilidad. En esa lógica, también se advierte una fuerte oposición entre quienes promueven la investigación «aplicada» frente a la investigación «pura» (Casanova y López, 2016, p. 47).

Finalmente, el paradigma utilitario del mercantilismo también ha hecho eco en los procedimientos internos de la institución universitaria, la cual vive una tensión entre sus modalidades tradicionales de gestión, frente a esquemas más corporativos y asimilación de criterios gerencialistas. En efecto, la gestión estratégica y orientada a resultados, el «pago por méritos» y los criterios propios de la mercadotecnia, se han introducido en la universidad de manera acrítica y sin considerar sus complejos efectos. Dicha metáfora también se hace presente en 
la vida universitaria mediante el énfasis puesto en la idea del «líder» capaz de obtener recursos, proyectos y contratos para promover el trabajo de su comunidad (Casanova y López, 2016, p. 48).

Frente a estos excesos del paradigma mercantilista, pienso que el extremo opuesto de la crítica se sitúa en la línea representada por Derridá (2002), quien defiende una universidad sin condición, por oposición a las concepciones funcionalistas que restringen el papel de la institución a una condición subordinada ante los mundos del hacer -el mercado- y el poder -la política-. Para dicho pensador, el énfasis en la enseñanza profesional y en los saberes «útiles» no ha representado sino el sometimiento de la universidad. Así, el reclamo filosófico es el de asumir que la universidad no solamente tiene el derecho a cuestionarlo todo, sino que la universidad es la institución social que tiene la obligación de hacerlo (Casanova y López, 2016, p. 48).

\section{PROPUESTA. LA VERDAD PRÁCTICA Y LA REVELACIÓN DEL HOMBRE EN EL TRABAJO}

Me parece que el panorama esbozado, plantea preguntas importantes para el presente y el futuro de la universidad: ¿cuál es la actitud que la universidad debe esbozar como respuesta? ¿Cuál es la vocación de la universidad ante las crecientes necesidades del mercado y su injerencia no siempre legítima? ¿Es posible conciliar la formación humanística, a la que está llamada la universidad, con las necesidades del mercado laboral, sin caer sometida y atrapada por la lógica de sus demandas instrumentalistas?

Desde luego, considero que parte de esta respuesta incluye la reafirmación de su vocación para la verdad. La universidad debe seguir siendo el espacio para el encuentro de la persona con las diversas áreas del conocimiento, en el marco de una educación humanista que no solo proporcione el «qué» sino el «por qué»; que no solo se remita a las causas inmediatas dentro de cada área propia del saber, sino que humanice ese saber al dotar de sentido esos mismos conocimientos a la luz de la verdad del hombre, su naturaleza y su condición antropológica de espíritu encarnado. Sin embargo, pienso que esta sacralidad del saber por medio del cual la persona se eleva incluso a lo trascendente -y que sin lugar a dudas encuentra en la universidad su templo-, no debe caer en la mentalidad de lo que María Pía Chirinos denomina «un humanismo aristocrático» (2011). Esto es, un humanismo, de origen aristotélico, que supone que la vida buena solo es posible para el hombre en la vida contemplativa, el ocio, o en todo caso, durante el ejercicio virtuoso en el ámbito de la polis, denostando, por contraposición, el negocio, término claramente negativo, que en este contexto adopta la realidad del trabajo.

En otras palabras, pienso que una forma de contrarrestar esta injerencia totalizante de las dinámicas del mercado -este «fundamentalismo del mercado», declaración verbal de Stiglitz, en el foro convocado por la Academia de Ciencias Sociales del Vaticano (2020)-, consiste en revalorizar la dignidad del trabajo, para la cual deberían ser preparados los estudiantes universitarios, como respuesta a su absoluta instrumentalización por parte de los excesos de la agenda neoliberal que prima en la vida de las instituciones sociales, pues redignificando el trabajo se comprende mejor el valor de la universidad que también participa en la formación para él. En lo que resta de la exposición llevaré a cabo una breve exploración de este aspecto, por considerar que puede tratarse de una vía nueva, que abone a otras ya existentes, para defender el valor intrínseco de la universidad y de su papel formativo, más allá de los condicionamientos del mercado. 
Un breve esbozo de la historia del trabajo y su valor nos muestra que, durante la Edad Media -momento dentro del cual nació la institución universitaria ${ }^{2}-$, el trabajo, clasificado bajo la categoría de vita activa, quedó eclipsado y subordinado por la vita contemplativa, modo de vida propio del religioso dedicado al estudio y contemplación, cuya actividad le permitía trascender la atención a las necesidades de la vida corriente para entrar en contacto con la eternidad (Arendt, 2005). Acompañando una lectura de la ya citada María Pía Chirinos (2011), al parecer, no es sino hasta la modernidad que en el imaginario occidental se atiende a una revalorización del trabajo como acto humano y humanizante, idea recuperada nominalmente tanto por el marxismo como por el cristianismo de manera explícita a partir del siglo XIX, aunque con antecedentes claros en pensadores como Kant. En este contexto, resultaría interesante explorar en qué medida la secularización del mundo post-ilustrado estuvo relacionado con ese cambio de concepción.

El problema radica en que, quizá tras la marcada exaltación de corte preponderantemente materialista del trabajo en el siglo XX, y ante el temor de que ello llegase a sofocar la dimensión del espíritu y sus manifestaciones, encontramos algunos autores que, en un movimiento pendular, retomaron la clásica contraposición entre vita activa y vita contemplativa, ya fuera para defender la superioridad de esta última como instancia de la libertad -es el caso de Josef Pieper en su gran ensayo El ocio y la vida intelectual-, ya sea para buscar dentro de la misma vita activa, alguna actividad que superase las cadenas del trabajo atado a la necesidad. Es el caso de La condición humana de Hannah Arendt (cfr. Chirinos, 2011). Vale la pena detenerse por un momento en esta última obra, pues sus elementos conceptuales sobre las diferentes categorías de la vita activa, no así todas sus conclusiones, me permitirán esbozar algunas pautas sobre la antropología del trabajo.

En La condición humana, Arendt distingue tres tipos de actividades humanas: la labor, el trabajo y la acción. Mientras la labor, modalidad más básica de interacción del hombre con el mundo, se manifiesta en acciones ordinarias, metabólicas, inexorablemente repetitivas, que acaban en productos que se consumen inmediatamente, el trabajo es reconocido como la confirmación del hombre en sí mismo por contraposición a la naturaleza, a la que domina mediante la labor. El trabajo, producto de nuestras manos, constituye al hombre en un homo faber, cuyo fin radica en «fabricar la interminable variedad de cosas cuya suma total constituye el artificio humano» (Arendt, 2005, p. 165).

Sin embargo, continúa Arendt, el trabajo está a su vez supeditado a una tercera actividad fundamental, la acción, identificada como aquella donde se percibe más claramente la diferencia cualitativa que separa al hombre del resto de la naturaleza: el momento en que el hombre desarrolla la capacidad que le es más propia, la capacidad de ser libre, de trascender lo dado. No es mediante el trabajo dominado por el criterio de utilidad, sino a través de la acción, guiada mediante la libertad, donde el hombre confirma su plena racionalidad.

Actuar, en su sentido más general significa tomar una iniciativa, comenzar (como indica la palabra griega archein), conducir, y finalmente poner algo en movimiento (que es el significado original del agere latino). [...] El hecho de que el hombre sea capaz de acción significa que cabe esperar de él lo inesperado, que es capaz de realizar lo que es infinitamente improbable (Arendt, 2005, p. 207).

\footnotetext{
No se olvide que la universidad nació en un momento en el que las artes liberales sobresalían por encima de las artes serviles o instrumentales, con el propósito de cultivar y profesionalizar a las primeras.
} 
Solo mediante la acción y el discurso (el logos, griego), los hombres pueden revelar activamente quiénes son, su verdadera identidad y hacer su aparición en el mundo -nuestro mundo- esencialmente humano. En contraste, el trabajo, aunque no está sometido a un ritmo cíclico interminable como la labor, no goza de la misma trascendencia que la acción, pues tiene un fin limitado: el uso duradero, pero agotable. «Tener un comienzo definido y un fin definido "predictible" es es el rasgo propio de la fabricación que, mediante esta sola característica, se diferencia de las restantes actividades humanas» (Arendt, 2005, p. 171).

El trabajo pues, no está al mismo nivel que la acción, porque la «estabilidad» $\mathrm{u}$ «objetualidad» del mundo artificial que se construye a través de él, no puede mantenerse sin que a su vez los fines logrados se erijan como medios para otros fines, dando lugar a una cadena infinita cuyo motor principal es el uso. Todo se presenta como instrumento para realizar algo más:

\footnotetext{
El homo faber, en la medida en que no es más que un fabricante y solo piensa en términos de medios y fines que surgen directamente de su actividad de trabajo, es tan incapaz de entender el significado [de fin en sí mismo] como el animal laborans de entender la instrumentalidad. Y de la misma manera que los útiles e instrumentos que usa el homo faber para erigir el mundo se convierten en el mundo del animal laborans, así la significación de este mundo, que realmente se encuentra más allá del alcance del homo faber, se convierte para él en el paradójico «fin en sí mismo» (Arendt, 2005, p. 179).
}

Esta actitud respecto del mundo, indica Arendt, explicaría por qué los griegos, en su período clásico, declararon que todo el campo de las artes y de los oficios -donde el hombre trabajaba con instrumentos para producir algo más-, era «banáusico», palabra cuya mejor traducción es la de «filisteo», es decir, vulgar de pensamiento y actuación de conveniencia (aunque asombra que de este calificativo quedaban excluidos los grandes maestros de la cultura y arquitectura griegas) (2005, p. 181).

En opinión de Arendt, el problema de esta actitud no radica como tal en la comprensión de una parcela de realidad, en términos de una mera racionalidad instrumental, sino en su absolutización como paradigma de la vida en su totalidad. En la medida en que las cosas se apoderan del proceso de la vida, solo para ser usadas, la productiva y limitada instrumentalidad de la fabricación se transforma en la ilimitada instrumentalización de todo lo que existe. La consecuencia es que la última esfera pública, el último lugar de reunión, relacionado al menos con la actividad del homo faber, es el mercado de cambio en el que exhibe sus productos. Pero esto, critica Arendt, implica seguir atados a la necesidad, a menos que haya también espacio para la acción y el discurso, para la realización de "grandes hechos y la articulación de grandes palabras» (2005, p. 195). Estas son las únicas actividades capaces de dejar huella en la vida del hombre en su sentido no biológico, por no estar supeditadas a la necesidad, sino ser expresión de la libertad; es decir de aquello más genuino y personal de cada ser humano, que permite distinguir a unos de otros por encima de las características comunes que nos identifican como miembros del mismo género humano. Por ello, señala Arendt, con el fin de que el mundo sea lo que siempre se ha considerado que debe ser -un hogar para los hombres durante toda su vida en la Tierra-, ha de ser un lugar apropiado para la acción y el discurso, para las actividades no solo inútiles por completo a las necesidades de la vida, sino también de naturaleza enteramente diferente de las múltiples actividades de fabricación con las que se produce el mundo y todas las cosas que cobija. 
Sin lugar a dudas la lectura de Arendt es novedosa lo mismo que inquietante. Frente a lo que ella denomina "glorificación teórica del trabajo», propuesta por la Modernidad, y que sin duda tiene en sus causas el gobierno omnipotente del mercado, pretende encontrar un espacio para la agencia humana que sea capaz de exponer la originalidad personal, ya sea a través del discurso o de la acción. Pero ello significa, paradójicamente, dejar el trabajo como actividad humana en las manos del mercado y sus leyes económicas, meramente instrumentales, con pocas posibilidades de una consideración antropológica. Como alternativa a esta lectura considero, en sintonía con Carlos Ruiz (2021), que el trabajo, aunque sometido a una dinámica instrumental como vehículo para la obtención de bienes determinados, también es escenario propicio para la acción, porque igualmente puede revelar la verdadera identidad, la auténtica naturaleza del ser humano.

De acuerdo con la tesis de Carlos Ruiz (2021), el trabajo, y en concreto el trabajo profesional, también puede ser clasificado como una acción humana en el sentido más pleno del término, cuyo origen es el hombre mismo en cuanto que es capaz de deliberación y elección. Su desenvolvimiento es posible gracias a la libertad y la voluntad del sujeto que lo ejerce, quien funge como su causa eficiente; por la misma razón, puede ser conducido y determinado hacia el bien o hacia el mal. Tal aseveración encuentra su ancla en cierta lectura de la naturaleza humana como principio y fin del actuar humano, cuyo germen se descubre, paradójicamente, en los clásicos.

Al trabajar, el hombre puede llevar a plenitud su racionalidad, al tiempo que construye su mundo, el mundo propiamente humano. A pesar de nuestra condición animal, no hemos desarrollado los dispositivos evolutivos apropiados para adaptarnos al ambiente, sino que nos hemos visto en la necesidad de transformar al ambiente, a este mundo originario en algo para nosotros; en cierto artificio que nos resulte humanamente habitable. Por medio del trabajo, el hombre pone la naturaleza a su servicio y la domina, sin que ello signifique explotarla -en un sentido negativo-, sino vivir en armonía con ella.

El trabajo, por tanto, también es un ámbito para el despliegue del logos y de la libertad, para la iniciativa y la acción, en el que puede quedar cristalizado lo originario, lo único e irrepetible, que brota desde lo más profundo de cada ser humano. Contrario a la perspectiva aristocrática que lo equiparaba con lo «servil», lo «vulgar» o lo «instrumental», el trabajo -y en particular, el trabajo profesional-, también puede ser un espacio para la afirmación personal; una vía de acción mediante la cual el hombre acredita su carácter novedoso y original en el mundo, que le permite distinguirse respecto de sus congéneres.

No vivimos únicamente sometidos al ciclo natural de la necesidad. También contamos con libertad que, expresada en el trabajo, ha sabido adaptar y construir sobre la necesidad para crear «un mundo de cosas» que ha adquirido un dinamismo hasta cierto punto autónomo de sus autores: instrumentos, hogares, ciudades, instituciones, gobiernos, empresas, todos productos del ingenio humano que necesitamos para sobrevivir. «Este carácter duradero de las cosas del mundo les da una relativa independencia respecto de los hombres que las producen» (Arendt, 2005, p. 166). Mediante el trabajo hemos construido nuestro mundo, un mundo esencialmente humano. En consecuencia, el trabajo se constituye en uno de los modos fundamentales de manifestación del hombre en la tierra, manifestación que además puede convertirse en fuente de identidad y distinción frente al resto de sus semejantes, pero también de los animales y del resto de la naturaleza. El trabajo, pues, emerge de la misma naturaleza del hombre y de su necesidad de plenitud.

Si el trabajo también es capaz de dejar huellas en la cultura o bien, de hacerse cultura; si la acción es capaz de abrirse a la novedad e indeterminación -lugar de manifestación de la libertad humana-, tiene sentido afirmar que la universidad también educa para el trabajo, 
un trabajo que posee una dignidad intrínseca que debe resistirse a una mera instrumentalización por parte del mercado. Al respecto, me parece de suma valía la reconciliación entre naturaleza y cultura propuesta por Spaemann, pues la naturaleza solo puede expresarse culturalmente (Spaemann, 1989). Por esto, se puede afirmar que las necesidades humanas siempre van acompañadas de una dimensión cognoscitiva, gracias a la cual el hombre es capaz de superar lo simplemente necesario, y aportar una dimensión artificial e incluso superflua respecto de la estricta necesidad. Alma y cuerpo, espíritu libre y necesidades básicas, mente y materia, lejos de reflejar un dualismo irreconciliable, nos proporcionan una imagen unitaria del ser humano (Chirinos, 2011).

El hombre es un ser natural que no solo en su pensar, sino también en su hacer, está abierto a lo absoluto. Tanto su capacidad de trabajo, al igual que la mera actividad intelectual, deriva más de sus potencias racionales que de su dimensión animal o material. La afirmación del hombre como animal racional, supone asumir que la diferencia específica del hombre -su racionalidad, aquello que lo distingue de los animales-, lo capacita lo mismo para pensar que para trabajar; para reflexionar que para actuar en la vida política. El hombre es el único ser que piensa, pero también, y a diferencia del resto de los animales que buscan adaptarse a la naturaleza que los rodea, el único que busca adaptar la naturaleza a él mediante el trabajo. El trabajo, por tanto, no es ajeno a la racionalidad, sino que es manifestación de ella por vía de la verdad práctica.

Aunque ciertamente, en consonancia con la filosofía clásica, existe un orden de jerarquía, donde la actividad contemplativa del intelecto es preeminente respecto de su actividad práctica, ello no supone demeritar la vida práctica, y a la verdad del intelecto que la acompaña -la verdad práctica- como secundaria o de menor categoría. La disociación, por no decir oposición, entre vida práctica y vida especulativa heredada quizá del tomismo (Ratzinger, 1972, p. 31), y presente en algunos neotomistas como Pieper, tiene uno de sus orígenes en la oposición entre las figuras bíblicas de la hacendosa Marta y la fervorosa María, lo mismo que en la jerarquización aristotélica de los usos de la razón. Pero su problema es que prescinden, tal como señalaba el entonces cardenal J. Ratzinger, de la interpretación que hacía san Agustín del mencionado pasaje evangélico para quien, más que imágenes de dos tipos de vida opuestos, el de la acción y el de la contemplación, representan el contraste entre la vida presente y la vida futura ${ }^{3}$.

En Santo Tomás, por el contrario, se cristalizará ese «cristianismo aristocrático», según el cual la vida activa, el trabajo, la racionalidad no teórica, se encuentra por debajo de la vida contemplativa, y esta toma de posición llegará hasta el s. XX (Chirinos, 2011).

Considero que la posible solución de toda esta serie de dualismos expuestos -vita contemplativa y vita activa, razón teórica y razón práctica, acción y trabajo- en cierto modo permiten abordar el dilema que parece abierto para el propio ámbito de la universidad, y con el cual comencé este trabajo, a saber: el de proporcionar una educación liberal o el de educar para satisfacer las necesidades instrumentales de la sociedad del conocimiento. Si no es posible la contemplación sin la actividad, y si el trabajo no solo es repetición sino acción, creo que también es posible conciliar la disyuntiva a la que se enfrenta la universidad, sin que sus fines queden expropiados por las necesidades -en cierto modo legítimas- del mercado.

\footnotetext{
Sobre esto, Ratzinger señala dos ideas que agrego como anotaciones al margen muy importantes. La primera es que Ratzinger supone que la subordinación de la vida activa a la vida contemplativa, en una especie de jerarquía inamovible, tiene lugar en Aquino debido a los límites que impuso sobre su pensamiento la ordenación por estamentos de la Edad Media (Ratzinger, p. 39). Lo segundo a apuntar es una idea de Gregorio Magno que retomo a propósito de esta distinción entre la vida activa y la vida contemplativa, pues el gran papa insiste en que nadie puede ser perfecto en la contemplación si no viene del trabajo de la obra activa. Puede uno sin duda entrar sin la contemplación en la vida eterna, pero no sin el trabajo (Ratzinger, p. 41).
} 
En concreto, la universidad puede encarnar los ideales morales que dan sentido al fin de la educación en el mundo laboral de la vida cotidiana, mediante la profesionalización de personas que buscan la verdad a través de sus actividades cotidianas. Así como para Newman la universidad es ese lugar de encuentro entre los saberes entre sí, y entre los saberes y el hombre, el trabajo profesional recobra su dignidad cuando no solo es mediatizado, sino redescubierto como lugar último de encuentro entre el saber y la sociedad a través del estudiante que simultáneamente aspira a ser un profesionista competente en el mundo del valor.

\section{REFLEXIONES FINALES}

La universidad tiene como fin propio la transmisión del conocimiento. Ser depositaria de la verdad, de una verdad abierta a la trascendencia (Sellés, 2013, p. 161). Pero la verdad no solo es teórica sino también práctica. E incluso, podemos hablar de una verdad técnica. Por una parte, el conocimiento cultivado por los saberes filosóficos e incluso teológicos -siguiendo la tesis de Ratzinger sobre el valor de la teología para la universidad-, es capaz de dotar de sentido el cúmulo de conocimientos teóricos, prácticos e incluso técnicos adquiridos en la universidad. Pero el valor de la verdad se hace sensible cuando es capaz de irradiar en el resto de las competencias aprendidas en el proceso de formación y profesionalización que adquiere el pupilo a lo largo de su carrera universitaria; cuando se valora el trabajo llevado a cabo tras ese período de aprendizaje universitario, y cuando, en este contexto, el ser humano deja de ser considerado como un trabajador cualificado para el que sus resultados ocupan una posición transitiva respecto de él, a un modo de expresión vital, que mediante su trabajo manifiesta su racionalidad, haciendo de la verdad aprendida, un servicio para la comunidad.

En contraste con un «humanismo aristocrático», para el que resulta impensable que la fuerza transformadora de la universidad se manifieste precisamente en el trabajo profesional y no solo en el estudio contemplativo, considero que la apertura a la novedad y el desenvolvimiento del logos o razón no solo es posible en el escenario del ocio, sino también del negocio. Una revalorización del trabajo a la luz del humanismo, permite a la universidad conciliarse consigo misma como educadora para el trabajo profesional, por ser el lugar de manifestación de la verdad no solo especulativa, sino también tanto práctica como técnica, al tiempo que escapa de las demandas omniabarcantes del mercado, que convierten al trabajador en módulo funcional.

La educación superior puede atender a las necesidades actuales de modernización e innovación, de resolución de problemas y de atención a la justicia de las sociedades contemporáneas, sin traicionar a su esencia, siempre y cuando no deje de apuntar al norte que orienta su brújula: ese espacio público en donde las personas se encuentran con la sabiduría. Sabiduría que, al impregnarse en el trabajador profesional que emana de la universidad, bajo la tutela de la verdad y el bien, puede irrumpir también hacia su mundo laboral, haciendo que se sobreponga a las dinámicas del mercado, sobre todo cuando antepone en primer lugar a las personas a las que sirve.

En conclusión, la necesidad de trabajadores cualificados que al mismo tiempo puedan responder críticamente al entorno primariamente utilitarista que los rodea requiere, por una parte, una reconsideración del papel de las humanidades en la formación que corresponde a 
la educación superior, pero a ello se suma una estrategia que me parece poco explorada aún y que consiste en una revalorización del trabajo profesional a la luz de su dignidad intrínseca, así como de sus posibilidades para alcanzar la verdad, una verdad de índole práctica, como respuesta a la instrumentalización y mercantilización del mismo.

\section{REFERENCIAS}

ARENDT. H. (2005). La condición humana, Barcelona: Paidós.

BECHER, B. (2019). Universities: The Neoliberal Agenda en Clack, B. y Paule, M. (eds). Interrogating the Neoliberal Agenda. The Limits of Success. Oxford: Palgrave Macmillan.

CASANOVA, C., LÓPEZ, G. (2016). Nuevos modelos de gobierno y gestión en la universidad. En Santos Rego, M. Á (ed). Sociedad del conocimiento: aprendizaje e innovación en la universidad. Madrid: Biblioteca Nueva.

CHIRINOS, M.P. (2011). Hacia una noción humana y positiva del trabajo. Tópicos (México). 40, julio-diciembre, pp. 195-222.

CLASSEN, P. (1983). Studium und Gesellschaft im Mittelalter, J. Fried (ed). Stuttgart: A. Hiersemann.

DERRIDÁ, J. (2002). Universidad sin condición. Madrid: Trotta.

GARCÍA DE FANELLI, A.M. (2000). La universidad pública frente a la nueva lógica de las políticas públicas y del mercado. Documento CEDES, CONICET-CEDES.

GALCERÁN, M. (2009). Reflexiones sobre la reforma de la Universidad en el capitalismo cognitivo. Nómadas, 27, octubre, pp. 86-97. Colombia.

HARVEY, D. (2007). Breve historia del neoliberalismo. Madrid: Akal.

JOVER, G. (2016). Aprendizaje y pragmatismo universitario en la sociedad del conocimiento. En Santos Rego, M. Á (ed). Sociedad del conocimiento: aprendizaje e innovación en la universidad. Madrid: Biblioteca Nueva.

LANUZA, G. (Febrero de 2021). Neo-Fascism as the Apparatus of Neoliberal Attack on Education: Towards a Pedagogy of Resistance. From Wisdom's Special Workshop to Factories of Knowledge: The Place of University in Culture and Society. The Second Kritik Conference. University of Santo Tomás (España). Manila, Filipinas.

NEWMAN, J. H. (1996). The Idea of a University. New Haven: Yale University Press.

RATZINGER J. (1972). El nuevo pueblo de Dios. Barcelona: Herder.

RÜEGG, W. (1992). A History of the University in Europe, v. 1, Ridder-Symoens (ed). Cambridge: Cambridge University Press.

RUIZ, C. (2021). La persona en la empresa y la empresa en la persona. Fundamentos teóricos para un estudio filosófico de la empresa en clave antropológica (en prensa).

SANDEL, M. (2020). La tiranía del mérito. ¿Qué ha sido del bien común? Debate. 
SANTOS REGO, M. A. (2016). Sociedades del conocimiento. Aprendizaje e innovación en la universidad (introducción). Madrid: Biblioteca Nueva.

SELLÉS, J.F. (2013). Los tres agentes del cambio en la sociedad civil. Familia, universidad y empresa. Navarra: Tribuna, Siglo XXI.

SPAEMANN R. (1989). Lo natural y lo racional: ensayos de antropología. Madrid: Rialp.

TÜNNERMANN BERNHEIM, C. y DE SOUZA CHAUI, M (2003). Desafíos de la universidad en la sociedad del conocimiento. Cinco años después de la Conferencia Mundial sobre Educación Superior. París: Comité Científico Regional para América Latina y el Caribe del Foro de la UNESCO. 